good table is set for five dollars and a quarter per week, a ticket system controlling the sale of meals. One second floor front room is furnished as a reception-room and the rest of the house is occupied by nurses' rooms. There are a few rooms for two nurses, but small rooms that members rent for thirteen dollars per month are the rule. The objection frequently urged against clubs-the lack of privacy-is practically obviated, as each apartment is distinct from every other, and so the coveted quiet resting place is found when a nurse enters her own room.

"The control of all club business has always been in the hands of the Alumno Association, the officers of the association being the Governing Board.

"We are proud to say that the end of the first year finds us in satisfactory financial condition, confident that the club meets a genuine need, and while from time to time something or other happens to remind us that we have not obtained ideal conditions, we have courage to face the future, with faith to believe that the answers to its problems will be found when the questions are fully stated.

"In closing this very incomplete account of nurses' attempts to make homelike dwellings for themselves I wish to thank those who have taken so much trouble to send me information and to express the hope that we may hear of many other successful efforts in this direction. Let us hope that the coming years may see the nurses even better comrades, and that, profiting by the experience of the past years, they will be successful in establishing clubs, fulfilling not only every requirement for food and shelter, but also serving the members and the community as centres of uplifting influences."

President.-As I have said before, it is with extreme regret that we are unable to call for discussion upon these papers, but the time is passing so rapidly, and we still have so much to do, that $I$ do not feel justifled in calling for discussion, much as we wish to; therefore we will pass on to the next paper and ask Miss Frederick for hers.

\title{
THE OPPORTUNITIES OF THE GRADUATE NURSE
}

\section{BY MATILDA A. FREDERICK}

The New York Training-School Alumno

"To the nurse who wishes to do real good and lasting benefit to mankind, as well as to maintain a growing bank account, there are many opportunities in the unexplored field of 'hourly nursing.' To the wealthy class of people the private nurse is always ready to cater, and many persons indulge in this expensive lurury upon the occasion 
of every slight indisposition, as well as serious illness, when not infrequently two to five nurses are employed. To the very poor the visiting nurse of city, church, or dispensary is ever ready to minister, but the so-called middle class of well-to-do people, whose income is not sufficient to employ a graduate nurse without great sacrifice, must either go without care in their homes or go to a hospital. So to this class of people the 'hourly nurse' would find it profitable to minister. A visit once or twice a day to give a bath, make the bed, take temperature, and such other ministrations as come properly within the province of a graduate nurse, with directions to some member of the family for giving medicine, is all that is needed in many cases.

"The charges for these visits is usually one dollar for the first hour and fifty cents for each additional hour, though some nurses charge one dollar an hour and some only one dollar a visit. Thus one has the advantage of a variety of patients and the daily outing in going from place to place, instead of the deadly monotony of constant attendance upon one individual, often querulous and exacting, taxing the patience and ingenuity of the nurse to provide entertainment and give satisfaction to family, friends, and a large circle of acquaintances. Two or three visits a day would be quite as remunerative as one private patient, with much more independence in living one's own life.

"That so little has been done in this department of nursing is said by some to be because there is no demand for it. But the demand certainly would be very great if there were a supply. Like every new field of labor, it must be intelligently worked up.

"One New York nurses' club has on its register nurses who will respond to calls for hourly nurses, as well as masseurs and nurses for operations. The latter named go into a house and prepare the room and patient for operation, taking with them everything necessary in the way of sterile linen, dressings, and towels, taking away all soiled linen, also furnishing basins, pitchers, etc., thus relieving the family of nearly all care and extra work, about all they have to furnish being plenty of boiled water. For this service the nurse charges from ten to twenty-five dollars.

"Of course, to secure calls for such cases one must be known to surgeons who require such service. One nurse whom I know in New York, after graduation spent one year in the operating-room of her Alma Mater, and then visited the largest hospitals at home and abroad that she might the better serve a large circle of surgeons from different schools. She obtained endorsement from those to whom she was personally known, then sent circulars to everyone whom she thought could possibly need her services, with the result of a very busy winter just 
past, making one hundred dollars a month. She also does hourly nursing, giving baths, rubs, douches, hot or cold packs, enemata, bladder irrigations, treatments, etc. But, as she expresses it, 'One must hustle' if success is to crown her efforts. Another nurse who has been some years in the work thinks there will be a great demand for hourly nursing when the people are educated up to it. Many persons tell her, 'Why! I can get a trained attendant for what I pay you, and have her all the time.' In places where this element is not to contend with, I am told there is a great demand for hourly nursing, and cities and country places outside of New York offer great opportunities.

"A good, all-round nurse will always have as much work as she can do in any small city or country town, with social adrantages that are not always hers in the large cities. I would urge the graduate nurses to cultivate these fertile fields.

"The Victorian Order of Nurses, instituted by Lady Aberdeen to commemorate the Diamond Jubilee of Queen Victoria, is intended to benefit any person whose means are not sufficient to employ a graduate nurse. A fee is charged ranging from five cents to fifty cents, according to the circumstances of the patient. The very poor are nursed without charge. The nurses do not attend infectious cases, but take maternity, medical, and surgical cases; also make preparation for and assist at operations and do surgical dressings.

"As a rule one nurse cares for three patients between the hours of eight A.M. and one P.M. The regular night nurse may be obtained for an eight-hour service. Emergency visits are also made, and confinements attended at night. To become a member of the order a nurse must have graduated from a recognized training-school for professional nurses, and must serve four months on probation. The order is supported by voluntary subscription and donations and fees received from patients.

"The Toronto branch has a home under the management of a lady superintendent, from which nurses are sent out, but only when the physician in attendance is willing to have the nurse care for his patient.

"Nurses residing in the home receive not less than twenty dollars a month for their services. Every nurse admitted to the order receives a bronze badge and a certificate of admission, and must wear the uniform of the order.

"In The Ammrioan Jodrnal of Nurging, September, 1903, a Victorian Order nurse very graphically gives some experiences of her work at Fort Frances, Ontario. Wittr the thermometer ranging from thirty to forty-five degrees below zero, she crossed a frozen river three times a day to risit a very sick patient on the American side, 'tramping 
through snowdrifts, crossing in fogs, getting fastened in the anchorice, and at times helping to break the ice.' She also states there is absolutely no poverty in Fort Frances, nor yet is there any very great wealth. But when a nurse is called to a patient, be it in a hotel or in his own home, hers is no easy task, for since the grown-up daughter, neighbor, or maid is absent, the entire work devolves upon the nurse.

"Let us then think less of the growing bank account, and more of the nobler and higher aims of our profession, remembering that

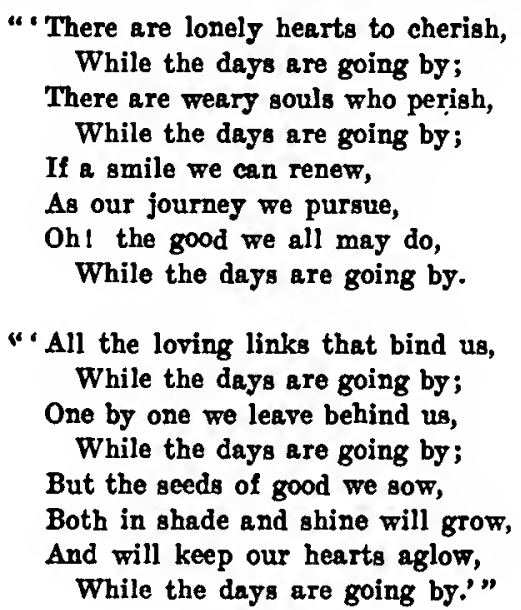

THE OPPORTUNITY OF THE NURSE IN PRIVATE DUTY

\section{BY MISS ANNIE RHODES New York City}

"The increase of the work in the hospital has extended the curriculum of the training-school, and the supervision thus made necessary has created many positions for the graduate nurse. This, however, while it may lessen the ranks of the private-duty nurse, benefits her materially, and it is the private nurse who, in the main, represents her profession to the world at large. Her opportunities for influencing the public are many, and the reputation of her school in particular, and her profession generally, is formed from the impression she herself creates. This important fact is not always realized sufficiently. The coming of the trained nurse into a family for the first time is anticipated with feelings of probable relief and possible trouble, for we are thought to be angels of mercy and hope or perfect terrors, as may be. The technical responsibility of the case, apparently, is the physician's. A nurse means one who is to carry out his orders carefully and properly. 